\title{
A formação social do arquitecto: Crise nos cursos de arquitectura, 1968-1969
}

The Social Education of the Architect: The 1968-1969 Crisis in Architecture

Courses

La formation sociale de l'architecte : crise dans les cours d'architecture, 1968-1969

\section{Gonçalo Canto Moniz}

\section{OpenEdition}

\section{Journals}

Edição electrónica

URL: http://journals.openedition.org/rccs/4163

DOI: $10.4000 /$ rccs. 4163

ISSN: 2182-7435

\section{Editora}

Centro de Estudos Sociais da Universidade de Coimbra

\section{Edição impressa}

Data de publição: 1 dezembro 2010

Paginação: 56-76

ISSN: 0254-1106

\section{Refêrencia eletrónica}

Gonçalo Canto Moniz, «A formação social do arquitecto: Crise nos cursos de arquitectura, 1968-1969 », Revista Crítica de Ciências Sociais [Online], 91 | 2010, posto online no dia 16 outubro 2012 consultado o 14 novembro 2019. URL : http://journals.openedition.org/rccs/4163 ; DOI : 10.4000/ rccs. 4163 


\title{
GONÇALO CANTO MONIZ
}

\section{A formação social do arquitecto: Crise nos cursos de arquitectura, 1968-1969*}

\begin{abstract}
A regulamentação da reforma do ensino da arquitectura em 1957 inicia um processo de transformações sucessivas no quotidiano dos cursos de arquitectura que irá culminar com uma crise no ano de 1969.

Ao longo de uma década de funcionamento, a nova orgânica proposta pela reforma não conseguiu, na sua globalidade, introduzir uma nova pedagogia nem democratizar o funcionamento das escolas, ficando refém do autoritarismo do Ministério da Educação. No entanto, a sua rigidez científica e administrativa estimulou professores e alunos a desenvolver estratégias, quer de projecto, quer de reflexão e debate, que procuraram promover a função social do arquitecto atento aos problemas da sociedade $\mathrm{e}$ da cidade, por oposição ao arquitecto tecnocrático.

Nos anos de 1968 e 1969 as duas escolas, tal como a universidade e a sociedade, politizam o seu discurso. Os estudantes e os professores reivindicam abertamente alterações profundas na gestão da escola, nos métodos pedagógicos e nos objectivos do ensino, exigindo a reforma da Reforma de 57.

Este texto aborda os momentos críticos deste processo de consciencialização política e social dos estudantes, que procura recolocar o papel da Escola no debate sobre a formação e sobre a profissão de arquitecto. No final de 1969 as escolas de arquitectura estão em crise, porque a universidade está em crise, mas também porque a profissão está crise.
\end{abstract}

Palavras-chave: arquitectura; crise académica; ensino da arquitectura; movimentos estudantis.

\section{Antecedentes: $1957-67$}

No final da década de 60, os cursos de arquitectura das duas escolas de belas-artes portuguesas vivem uma crise, que se vai agravando com vários acontecimentos em 1968 e 1969. Numa perspectiva mais alargada, esta situação tem raízes no ano de 1957 e na promulgação da reforma do ensino

\footnotetext{
* Este texto enquadra-se na investigação para a tese de doutoramento "O Ensino da Arquitectura em Portugal: 1932-1974", que tem o apoio da FCT.
} 
da arquitectura pelo ministro Leite Pinto. A recepção do Decreto-lei n. ${ }^{\circ}$ 41.362 (Reforma de 57), de 14 de Novembro de 1957, seria contaminada pelos acontecimentos balizados entre as eleições de 1958 e a crise académica de 1962, que alteraram o quadro da oposição às políticas do regime.

\section{A recepção à Reforma de 57}

Nas duas escolas de arquitectura do país, a regulamentação da reforma do ensino artístico em Novembro de $1957^{1}$ corresponde, por um lado, à clarificação de um processo aberto em 1950 para acabar com o ensino beaux-arts e consagrar o ensino moderno e, por outro, à implementação de um conjunto de transformações que desde o primeiro momento provocaram um aceso debate sobre a formação do arquitecto e a sua função na sociedade.

A nova reforma pretende colocar em paridade a função artística do arquitecto com a função técnica, como refere a Lei de 1950:

[O] estudante de arquitectura tem de acompanhar a evolução das ciências e das aplicações destas na medida em que lhe oferecem novas possibilidades de realizar as suas criações $[\ldots]$ modernizar o ensino sem lhe fazer perder o carácter artístico. (Lei n. $\left.{ }^{\circ} 2.043,1950\right)$

Pretendia-se assim dar resposta à estratégia de fomento do governo, que procurava promover o desenvolvimento industrial, a construção de infraestruturas e o crescimento das cidades. $\mathrm{O}$ aumento exponencial da população urbana no final dos anos 50 massificou todos os sectores da actividade económica, exigindo a criação de um corpo de arquitectos, apto a encontrar soluções para os problemas sociais e a responder tecnicamente aos desafios da nova indústria da construção.

A Reforma de 57 pretende aproximar a Escola de Belas-Artes do modelo universitário, apostando na vertente pedagógica mas também na vertente cultural, como "centro de irradiação artística", e na vertente de investigação, através de "cursos de especialização" e de um centro de estudos. Este novo dimensionamento da Escola é sustentado por um alargamento do corpo docente, que passa a incluir a figura do assistente, e pela integração do professor-investigador, em paralelo com o tradicional professor-projectista.

Nas duas escolas, a nova reforma irá obrigar à redefinição dos conteúdos das disciplinas, à implementação de novos métodos de trabalho e à

\footnotetext{
${ }^{1}$ A reforma do ensino artístico é promulgada em Junho de $1950 \mathrm{com}$ a Lei n. ${ }^{\circ} 2043$, mas só é regulamentada em 14 Novembro de 1957 , com o decreto n. ${ }^{\circ} 41.363$. Ficou conhecida como a Reforma de 57.
} 
diversificação do corpo docente. A adaptação à nova reforma fica, assim, na mão dos novos assistentes, enquanto os professores já em fim de carreira mantêm em actividade as cadeiras da antiga reforma até meados da década de 60.

A Reforma de 57 é exaltada pelos professores, que ansiavam por esta remodelação do ensino desde 1950, encarada com expectativa pelos estudantes e criticada pelos arquitectos.

$\mathrm{Na}$ Escola Superior de Belas-Artes do Porto (ESBAP), o director Carlos Ramos $^{2}$ começa por considerar que a reforma é "o maior acontecimento das últimas décadas no campo das belas-artes" (Ramos, 1957:3), mas, no ano seguinte, ao tomar consciência dos problemas decorrentes da sua aplicação, salvaguarda que "Roma e Pavia não se fizeram num dia" (Ramos, 1958: 4).

$\mathrm{Na}$ Escola de Lisboa (ESBAL), o director Paulino Montez 3 partilha do mesmo entusiasmo, escrevendo no Boletim da ESBAL, "Os dois diplomas - o de 1950 e o de 1957 - constituem uma só obra, que há-de ficar, assim o supomos, na história do ensino artístico em Portugal, como assinalado padrão" (Montez, 1959: 36), não integrando, ao contrário do seu homólogo do Porto, as críticas que começavam a surgir à sua volta.

Os estudantes do Porto confiam, num primeiro momento, no entusiasmo do director da Escola, enquanto os de Lisboa lançam um inquérito aos professores de arquitectura na revista VER sobre o seu posicionamento perante a nova reforma. ${ }^{4}$ Esta expectativa está já abalada passados dois anos, como se vê na crítica à reforma expressa pelos alunos do $4^{\circ}$ ano da ESBAL, num depoimento na revista Arquitectura: "Efectivamente, o estatuto da nova orgânica esboça uma harmonia irreconhecível no quotidiano escolar" (Gravata, 1961: 41).

As críticas acompanham também um conjunto de depoimentos solicitados pela revista Arquitectura sobre a nova reforma: Francisco Keil do Amaral, José-Augusto França e José Pacheco consideram tratar-se de uma

\footnotetext{
${ }^{2}$ Carlos João Chambers Ramos (1897-1969) forma-se em arquitectura na EBAL entre 1915 e 1922. Em 1932 concorre ao concurso para professor da $4^{a}$ cadeira na EBAL, mas seria preterido por Luís Cristino da Silva. Em Outubro de 1940, a Escola de Belas-Artes do Porto convida-o para professor da $4^{a}$ cadeira, cargo que iria exercer até ao seu jubileu, em Janeiro de 1967. De 1952 a 1967 foi director da EBAP.

${ }^{3}$ Paulino António Pereira Montez (1897-1988) forma-se em Arquitectura na EBAL em 1922. Com Carlos Ramos e Cassiano Branco, concorre em 1932 ao concurso para professor da $4^{a}$ cadeira da EBAL. Em Maio de 1946, na sequência da criação das cadeiras de Urbanismo, o Conselho Escolar da EBAL convida-o para professor da $16^{a}$ cadeira. Em Dezembro do mesmo ano é nomeado subdirector da EBAL e em Março de 1949 passa a director, cargo que exerceu até 1967, ano em que se jubilou. ${ }^{4}$ O inquérito é publicado na revista Ver (Setembro 1959), com os depoimentos de Paulino Montez, Luís Cristino da Silva, Read Teixeira, Alberto José Pessoa e Rafael Botelho. Todos encaram a nova reforma como uma oportunidade, como refere Pessoa, para interessar "professores e alunos na revisão de métodos didácticos", ou seja, "na maneira como ele [ensino] é orientado [...] para o estudo e resolução dos problemas actuais da construção e do urbanismo".
} 
reforma "requentada" e "misteriosa", esvaziada de qualquer debate sobre a "reforma de mentalidades e de processos didácticos" (Amaral, 1958: 43).

Este descontentamento com a Reforma de 1957 deve-se, também, ao adiamento político a que esta foi sujeita desde 1950, conduzindo naturalmente à sua desactualização. Nessa data, 10 de Julho de 1950, a reforma teria substituído apropriadamente o sistema beaux-arts por um sistema moderno, de acordo com as propostas quer das escolas, quer dos arquitectos, quer das instâncias internacionais, como os CIAM. ${ }^{5}$

Perante este impasse, entre 1950 e 1957, os professores foram transformando o quotidiano nas escolas, pondo em funcionamento um sistema híbrido, onde o currículo beaux-arts acolheu um ensino moderno.

No entanto, a consagração deste ensino moderno em Novembro de 1957 confrontou-se com uma reacção crítica aos modelos do movimento moderno, com uma oposição crescente à política educativa do Estado Novo, que culminaria na crise de 62 e com a reivindicação de novos métodos pedagógicos, como reclamam os alunos de Lisboa, citando ainda Ortega y Gasset, "a reforma é sempre criação de novos usos" (apud Gravata, 1961:38). Todo o sistema pedagógico positivista começa a ser questionado, apelando-se à democratização da universidade e à formação social do arquitecto.

A reivindicação pela Reforma de 57 transformou-se rapidamente na contestação da Reforma de 57.

\section{Novos métodos de ensino: "conhecer para compreender"}

A Reforma de 57 organiza o ensino em três ciclos, partindo de uma fase generalista e analítica com grande diversidade disciplinar até uma fase de especialização mais profissionalizante, que culmina num relatório de estágio. Nas escolas, perante um currículo que se divide entre disciplinas artísticas, leccionadas nas escolas de belas-artes e disciplinas científicas, que arrastam os alunos para as faculdades de ciências, caberá aos novos assistentes encontrar um espaço de renovação nas disciplinas de Arquitectura Analítica, Composição de Arquitectura e Teoria e História da Arquitectura.

No Porto, Octávio Lixa Filgueiras, Arnaldo de Araújo e mais tarde Álvaro Siza introduzem o método analítico, como instrumento de investigação projectual e os estudos urbanos, como objecto de trabalho do arquitecto. Os

\footnotetext{
${ }^{5}$ No Congresso Nacional dos Arquitectos de 1948, um conjunto de arquitectos denuncia as condições vigentes nas escolas de arquitectura, reclamando uma nova orientação pedagógica. Tal processo decorre também nos CIAM, impulsionado por Walter Gropius, Siegfried Giedion e Ernesto Rogers. No ano seguinte, o ministério organiza uma comissão para estudar a reforma do ensino artístico com os professores das duas escolas de Belas-Artes e com o professor do IST, Porfírio Pardal Monteiro. O relatório desta comissão deu origem à Lei n. ${ }^{\circ} 2043$ de 10 de Julho de 1950.
} 
trabalhos escolares abandonam os temas abstractos e focam-se em zonas urbanas com problemas reais e socialmente complexos - o centro histórico, os bairros sociais ou as áreas de expansão.

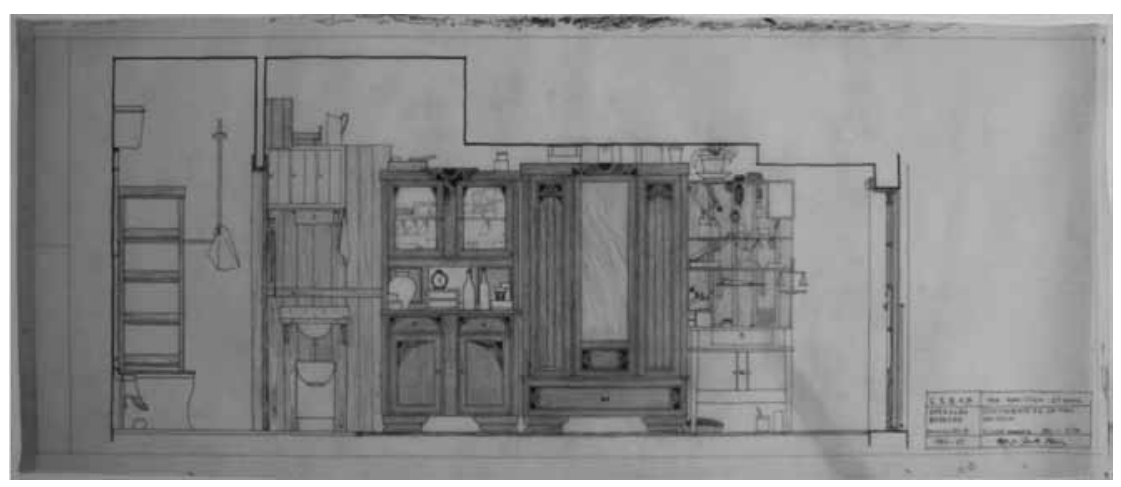

Jorge Canto Moniz, “Operação Barredo - Levantamento de um fogo dos Arcos”, Arquitectura Analítica I, ESBAP, Professor Octávio Lixa Filgueiras, 1964-65 Arquivo CDUA-FAUP, ARQAN1-009-PR10-13-2

Em Lisboa, o mesmo caminho é seguido por Frederico George para quem "o método de trabalho na arquitectura apoia-se sobretudo na análise, que prepara o estabelecimento de uma síntese que conduzirá à criação" (George, 1964: 78) e depois por Nuno Portas, que nas cadeiras de composição propõe trabalhos "onde a dificuldade em programar é desde logo um dado do programa” (Portas, 1968: 110).

Tratava-se, assim, de "conhecer para compreender", procurando a função social do "arquitecto-anti-lápis-maravilhoso", para utilizar as expressões de Filgueiras fixadas na sua tese $A$ Função Social do Arquitecto, de 1962 (Filgueiras, 1985).

Esta mesma consciência social provocada pelos professores teve reflexo na participação associativa dos estudantes na crise de 62 , que alinham com os seus colegas da universidade nas lutas estudantis, como aliás sempre o fizeram, com o objectivo comum de legalizar a associação de estudantes e de lutar pela autonomia da universidade.

Este associativismo manifesta-se em diversas publicações, quer do Porto, o ESBAP (Janeiro de 1962), quer de Lisboa, a VER (1954-66) e a ESBAL 63 (Março de 1963), como embriões das pró-associações de estudantes onde os artigos mais politizados sobre o ensino e o associativismo convivem com a reflexão crítica sobre arquitectura, arte e especialmente cinema.

Dez anos depois da sua implementação, o currículo moderno, proposto pela Reforma de 57, estava já substancialmente subvertido, funcionando 
como suporte de experiências individuais perante a incapacidade de articulação e coordenação de uma grande diversidade de disciplinas. Este "somatório de cadeiras", espalhadas por diversas instalações universitárias e com professores "emprestados", não conseguiu apoiar uma perspectiva mais globalizante do projecto que conciliasse quer uma visão antropológica e humanista, quer uma visão mais tecnológica e científica.

Neste sentido, é através do projecto que a Escola se interessa pelos problemas reais da sociedade, tomando contacto com as populações e estudando o património arquitectónico das cidades. Este confronto com o "real" uniu política e socialmente alunos e estudantes, criando uma plataforma de entendimento consciente dos novos desafios que se colocavam à profissão e consequentemente à Escola.

A saída da última geração de mestres em 1967 - Carlos Ramos no Porto e Paulino Montez e Cristino da Silva em Lisboa - criou um espaço de debate, que a sua presença tutelar havia sempre anulado, possibilitando agora a exploração de outras estratégias de ensino e de actuação do arquitecto.

A Reforma de 57 e, também, todo o contexto nacional dos anos 60 foram espaço de formação de uma forte consciência cívica, política e social que se revelou um instrumento operativo para enfrentar os debates que os anos de 68 e 69 iriam gerar.

\section{Espaços de contestação: 1968 e 1969}

O ano de 1968 é um ano de viragem no mundo, em Portugal, na universidade e nas Escolas de Belas-Artes: em Janeiro, a ESBAL e a ESBAP começam o ano com novos directores, tendo Paulino Montez e Carlos Ramos atingido o limite de idade; entre Janeiro e Agosto, a Primavera de Praga questiona a ordem política mundial; em Maio, Paris é o palco privilegiado dos movimentos estudantis de contestação aos regimes autoritários e à sociedade capitalista; em Agosto, António Oliveira Salazar é substituído por Marcelo Caetano; em Dezembro, a Associação Académica de Coimbra reorganiza-se para preparar as eleições de 69. Para os estudantes de arquitectura, este quadro político, social e educacional, vai criar condições para uma forte consciência política, direccionada para a reforma do ensino da arquitectura e da formação-função do arquitecto.

\section{Boletim ESBAP: a autogestão}

$\mathrm{Na}$ ESBAP, o processo de renovação da direcção, com o jubileu de Carlos Ramos no início de 1967, abre brechas profundas nas paredes da Escola. A solução encontrada, já em Julho de 1967, com a nomeação do velho 
professor de Geometria, António Cândido de Brito, ${ }^{6}$ é a mais conveniente para o governo e a menos estimulante para alunos e professores, rompendo-se o elo de compromisso e solidariedade que caracterizava a Escola de Carlos Ramos. O Director António de Brito não tem capacidade para negociar a situação contratual dos assistentes e acaba por ceder à pressão do governo para controlar a actividade associativa, como foi exemplo o encontro entre a ESBAP e a ESBAL, realizado no Porto em Maio de 68, onde os professores foram impedidos de reunir com os alunos, para debater os problemas do ensino (Boletim ESBAP, 2, 1968: 1).

A reacção dos estudantes é imediata, com a publicação em Junho de 68, também no rescaldo dos acontecimentos de Paris, do segundo número do Boletim ESBAP, ${ }^{7}$ que tinha o objectivo de "dialogar sobre os nossos problemas integrados nos da nossa sociedade [...] que agite com o imobilismo que se radicou na nossa escola [...] que seja uma tomada de consciência dos nossos problemas, como estudantes, como profissionais e como homens radicados na realidade portuguesa" (Boletim ESBAP, 2, 1968: 1). O boletim mantém a vertente culturalista que legitima, junto da censura do governo, as publicações das associações de estudantes, mas afirma a sua componente política, analisando o panorama internacional e estimulando $\mathrm{o}$ associativismo.

O ESBAP 2 dedica duas páginas aos "Acontecimentos Estudantis Internacionais" porque "Todos estes movimentos, que alastram por grande parte do mundo [...] têm um determinado número de analogias" (ibidem: 4-5). São notícia os acontecimentos nas universidades de Turim e de Roma, com a luta pela autogestão (4) e a crise de Maio de 68 em França, onde "um facto evidente era a união entre professores e estudantes, já que uns e outros reclamavam uma reforma para um Ensino que não correspondia às suas aspirações legítimas [...] exigindo a auto-gestão estudantil e a democratização do ensino" (ibidem, 1968: 5).

Este boletim é o primeiro passo dos estudantes para uma reivindicação organizada ao sistema de ensino vigente, procurando envolver todo o corpo discente e demonstrando as potencialidades de uma gestão partilhada por

\footnotetext{
${ }^{6}$ António Maria Cândido de Brito, filho de José de Brito (1855-1946), professor de Desenho, forma-se em arquitectura em 1926 e entra na ESBAP para professor do $1^{\circ}$ cadeira, Geometria Descritiva e Estereotomia em 11 de Janeiro de 1940, sendo nomeado director em Julho de 1967, cargo que exerceu até 25 de Abril de 1974.

7 Para além deste conjunto de notícias, o ESBAP 2 segue os jornais de outras associações de estudantes, onde se exploram três secções: a informativa, a formativa e a cultural. A participação de José Pacheco Pereira aborda o debate teórico em torno do neo-realismo com o artigo "Do realismo como inexistência", em contraponto com o artigo "Do realismo com existência", de J. A. Pires.
} 
professores e alunos, com exemplos concretos. A ideia da autogestão vai ganhando consistência como única via possível para a democratização do ensino e consequente reforma das práticas e métodos pedagógicos.

\section{"Aula Magna"}

No final de 1968, professores e alunos debatem intensamente a situação do curso de arquitectura, perante a ausência de uma direcção forte com capacidade negocial junto do Ministério.

Em Agosto de 68, enquanto Marcelo Caetano substituía Salazar, os professores escrevem ao Ministro da Educação Nacional, José Hermano Saraiva, reclamando pela revisão dos seus contratos e respectivas provas públicas. ${ }^{8}$ Perante a iminente "extinção da escola", os professores propõem ainda a criação de um grupo de trabalho para promover uma experiência pedagógica, com base no Decreto n. ${ }^{\circ} 47.587$ de 1967, ${ }^{9}$ com o objectivo de repensar a reorientação do ensino. ${ }^{10}$

Os alunos aproveitam a inquietação dos professores e, no arranque do ano lectivo, substituem as aulas por reuniões diárias conjuntas, denominadas "aulas magnas", para discussão dos problemas pedagógicos e administrativos da Escola. Estas reuniões culminam com a elaboração de uma petição entregue em mão ao Ministro, onde se exige: "Autonomia funcional para que a Escola possa [...] introduzir [...] as alterações e inovações que em cada momento se revelarem aconselháveis" ${ }^{11}$

Pressionado pelo clima de abertura criado por Marcelo Caetano, o ministro José Hermano Saraiva desloca-se três dias depois à Aula Magna da ESBAP para participar na reunião com alunos e professores. Os alunos apresentam de novo a referida petição e os professores, solidários com os alunos, focam a sua intervenção em "três aspectos mais relevantes - carreira, problema económico e investigação", solicitando uma "experimentação permanente" e o apoio financeiro ao Centro de Estudos de arquitectura. $\mathrm{O}$ ministro ignora as propostas de alunos e professores e discursa sobre o apoio da escola à sociedade, concluindo a intervenção com um elogio ao clima "verdadeiramente universitário", que se vive na ESBAP. ${ }^{12}$

\footnotetext{
${ }_{8}$ A ESBAP deveria ter 24 professores e 12 assistentes e tem apenas 5 professores e 26 assistentes. ${ }^{9}$ Decreto-lei n. $^{\circ} 47.587$, de 10/3/1967, art. 2 ${ }^{\circ}$, "O Ministério da Educação Nacional fixará em despacho, caso a caso, as regras a que devem obedecer as experiências, podendo, para isso, dentro do âmbito destas, introduzir nos regimes gerais em vigor as modificações ou adaptações que se tornem necessárias".

${ }_{10}$ AEESBAP, Informação 3, ESBAP - 1968, Problemas e Processos, 4 de Dezembro de 1968,

F. Arquivo Pedro Ramalho.

${ }^{11}$ Idem, E.

${ }^{12}$ Idem, 5-6.
} 
Até ao final do ano lectivo, a Escola, perante a inacção do ministério, mobiliza-se na reflexão sobre a sua actual situação do ensino e principalmente sobre a sua perspectiva de futuro, desenvolvendo também algumas experiências pontuais nas cadeiras de arquitectura. Na Arquitectura Analítica, Filgueiras insiste no método analítico com a IV Operação Barredo e no $3^{\circ}$ ano, na Composição de Arquitectura, Arnaldo Araújo experimenta outras possibilidades metodológicas, de carácter estruturalista, com o tema "Uma casa é uma casa", tendo como base uma proposta da revista Casabella sobre modulação e habitat (Hultberg e Seablom, 1968: 20-45).
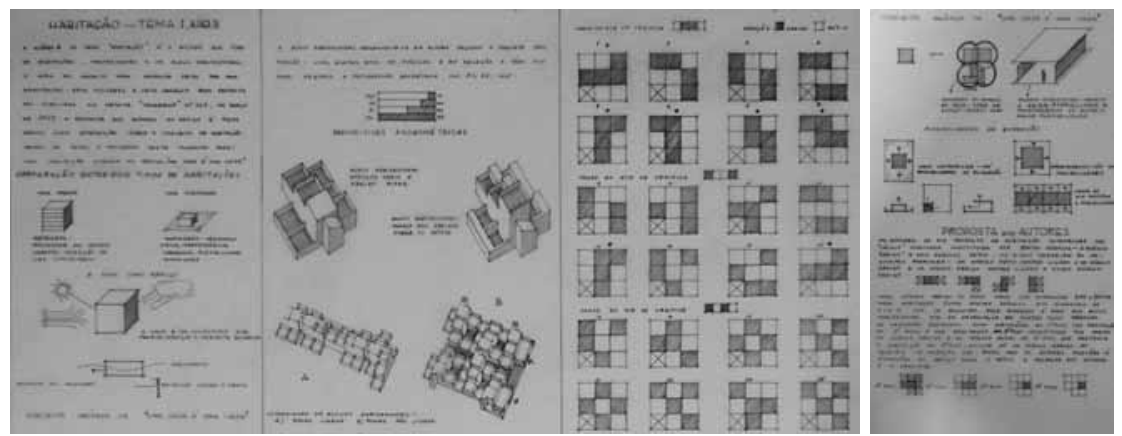

António Dias, "A minha casa é uma casa", Composição de Arquitectura I, ESBAP, Professor Arnaldo Araújo, 1968-69. Arquivo CDUA-FAUP, COMPARQ1-002-1-4

Paralelamente, extremam-se as posições dos alunos e professores. Por um lado, os alunos em diversas reuniões gerais reivindicam um "sistema de diálogo e acção" ${ }^{13}$ entre docentes, discentes e direcção. Por outro lado, os assistentes, ${ }^{14}$ após reuniões sucessivas desde Maio de 1969, assumem uma posição de força ao declarar a sua indisponibilidade para leccionar no ano lectivo seguinte: Fernando Távora diz-se "desencantado"; Arnaldo Araújo "não encontra qualquer perspectiva convincente, ou pelo menos sugestiva, para a sua continuação na Escola"; Álvaro Siza "considerando vantajoso certos docentes praticarem o exercício da profissão liberal, não encontra nas condições vigentes possibilidades de compatibilizar esses dois aspectos (ensino e profissão) para si essenciais". ${ }^{15}$ Perante estas posições, as aulas

\footnotetext{
${ }^{13}$ Um grupo de alunos, “À direcção, corpo docente e estudantes da ESBAP”, 5 de Março de 1969, p. 1. Arquivo Pedro Ramalho.

${ }^{14}$ Em reunião realizada no Sindicato Nacional dos Arquitectos, os assistentes que se declaram indisponíveis para continuar a leccionar são: Fernando Távora, José Carlos Loureiro, Arnaldo Araújo, Cristiano Moreira, Álvaro Siza, Duarte Castel-Branco, Alfredo Viana de Lima, Jorge Gigante e Pedro Ramalho. Filgueiras, o único arquitecto com lugar no Conselho Escolar, informa que está a ponderar também o afastamento. 15 Octávio Lixa Filgueiras, Carta ao Director da ESBAP, 16 de Julho de 1969, p. 2. Arquivo Fernando Távora.
} 
do ano lectivo 1969-70 no curso de arquitectura da ESBAP não têm início, provocando uma crise académica mas também política, que transborda para a opinião pública com um comunicado dos alunos aos jornais, onde denunciam a situação alarmante que se vive na Escola: "Não há professores, não há aulas, não há diplomados". ${ }^{16}$

Ao longo dos anos de 1968 e de 1969, os alunos e os professores de arquitectura conquistam um espaço de debate e de intervenção na vida política da escola, começando por obrigar o ministro a deslocar-se às suas reuniões magnas e acabando por suspender o funcionamento curso.

A vida pedagógica da Escola é contaminada pela acção política, sendo os instrumentos de projecto, como o desenho, substituídos pelos manifestos e pelas reuniões. Perante o inevitável fracasso do sistema de ensino a resolver os problemas e as aspirações de professores e alunos, o fim da Reforma de 57 tornou-se também uma questão simbólica, um slogan ou arma de arremesso político. O fim da Reforma de 57 e o fim dos seus métodos de ensino, fixados na expressão "recusa do desenho", representavam também o fim de um modelo de arquitecto, ao serviço do Estado e das empresas, o arquitecto técnico. A Escola impunha assim à classe dos arquitectos uma discussão séria sobre a função do arquitecto na sociedade, ao serviço das populações, e consequentemente sobre a orientação do ensino na formação desse outro arquitecto. Neste sentido, na Aula Magna, mais do que contestar a Reforma de 57, procurava-se reivindicar um novo sistema de ensino, mas também um novo arquitecto, que só o encerramento do curso de arquitectura poderia reclamar.

\section{"O concurso e a ESBAL"}

A utilidade maior deste concurso terá presidido, porventura, no facto de muitos, se terem dado conta da crise que aquele ensino atravessa, promovendo-se uma tomada de consciência que alguns desejariam prolongar em formas de intervenção. (Duarte, 1968: 179)

Na ESBAL, a substituição de Paulino Montez pelo escultor Joaquim Correia na direcção da Escola, em Janeiro de 1967, é também acompanhada pela renovação das cadeiras de Composição de Arquitectura com a saída de Luiz Cristino da Silva, em Maio de 1966, por limite de idade. Nuno Portas, assistente da Escola desde 1964, assume a regência das

${ }_{16}$ Alunos do Curso de Arquitectura, "Situação da Escola de Belas Artes", 24 de Novembro de 1969, p. 2. Arquivo Pedro Ramalho 
cadeiras de Composição de Arquitectura I, II e III, integrando em Janeiro de 1968, dois novos assistentes, Francisco Silva Dias e Bartolomeu da Costa Cabral. ${ }^{17}$

Ainda em Janeiro, a Escola abre o concurso para o lugar de professor do $1^{\circ}$ grupo, arquitectura, ao qual concorrem Nuno Portas, Sebastião Formosinho Sanchez e Raul Hestnes Ferreira. A candidatura de Raul Hestnes é recusada e o lugar de professor é entregue ao professor mais velho, Formosinho Sanchez, sendo preterido Nuno Portas, apesar do reconhecimento do júri e da Escola do seu mérito absoluto. Perante esta decisão, o concurso é profundamente mediatizado dentro da escola, arrastando consigo novamente a contestação dos alunos à direcção e ao sistema de ensino, e fora da escola, com sessões de debate no sindicato que dão origem a um editorial na revista Arquitectura, com o título "O concurso e a ESBAL" (Duarte, 1968: 179). Os arquitectos consideram que a crise na Escola se deve a um sistema tradicional de compartimentação em vasos estanques e a uma formação tripartida (Engenheiro, Historiador e Artista), propondo uma efectiva colaboração entre docentes e destes com os alunos, de modo a construir um sistema de "continuidade e diálogo interdisciplinar" onde se introduza, por exemplo, "o ensino das cadeiras teóricas na prática de projecto", tal como propõe Bruno Zevi (apud Duarte, 1968: 230).

Tal como no Porto, os alunos de Lisboa reactivam as acções associativas em Dezembro de 1968 e reivindicam a sua representatividade junto da Direcção da Escola e ainda a autonomia da arquitectura face às restantes Artes,$^{18}$ procurando participar na gestão dos problemas pedagógicos. Estas acções estendem-se às salas de aula, com a realização de performances e actividades culturais, como a tradução do manifesto situacionista, que neste período circulava na Escola.

Paralelamente, os assistentes de Composição de Arquitectura (Portas, Costa Cabral e Silva Dias) iniciam um conjunto de acções tendentes a alterar o funcionamento das cadeiras do $1^{\circ}$ grupo. Em Março de 69, dirigem à direcção da Escola um documento exigindo "uma urgente clarificação que permita uma colaboração ampla e construtiva de todos os elementos do corpo docente na Escola, de modo a estimular o clima de confiança

\footnotetext{
${ }_{17}$ Segundo o Livro de Actas da ESBAL, as propostas de contratação de novos assistentes são constantemente não autorizadas, ou pelo Director ou pelo Ministro. Em 25 de Agosto de 1965, o Director propõe (Bartolomeu) Costa Cabral e Marçal Grilo. Em 31 de Outubro de 1966, Frederico George propõe Nuno Teotónio Pereira, que não é autorizado. No ano seguinte, Frederico George propõe Silva Dias e novamente Costa Cabral para preencher a vaga libertada com a saída de Alzina de Menezes, que terá entrado em 1966.

18 Sindicato Nacional dos Arquitectos, "Resenha dos principais factos relacionados com a actual crise da ESBAL”, 1970, p. 1. Arquivo Francisco Silva Dias.
} 
mútua, indispensável ao progresso do ensino". ${ }^{19}$ Neste sentido, elaboram propostas concretas de flexibilização do sistema de ensino: colaboração de personalidades exteriores à escola (Manuel Tainha, José Augusto França, J. P. Martins Barata); adequação do regime de funcionamento das aulas de acordo com as exigências dos trabalhos; coordenação vertical e horizontal; integração de novos assistentes; divulgação dos trabalhos escolares. ${ }^{20}$

Finalmente em Outubro, perante o início do ano lectivo e ainda sem resposta da direcção, Nuno Portas apresenta a sua demissão por considerar que não estão reunidas "as condições mínimas de estatuto que permitiriam o desenvolvimento de um trabalho pedagógico não satisfatório, mas pelo menos aberto e consequente". ${ }^{21}$

Por um lado, a demissão de Nuno Portas na ESBAL foi um caso isolado, ao contrário das demissões na ESBAP, que envolveram todos os assistentes de arquitectura. Por outro lado, as reivindicações dos estudantes na ESBAL não atingiram a dimensão dos plenários realizados na Aula Magna da ESBAP. No entanto, o clima de crise estava criado e as duas escolas chegavam ao final de 1969 sem condições para iniciar o ano, por demissão dos principais assistentes e pela contestação dos próprios alunos à direcção da escola, ao sistema de ensino e à própria universidade. Esta crise, tal como outras que decorriam na universidade, levaram à demissão do ministro José Hermano Saraiva, obrigando o novo ministro, Veiga Simão, a uma negociação aberta para o estabelecimento de regime de experimentação e de preparação de uma nova reforma com o apoio das duas escolas.

\section{Encontros: 1969}

Neste ambiente de contestação, estudantes, professores e arquitectos participam activamente nos dois encontros de arquitectos realizados no ano de 1969. O primeiro, o "II Encontro de Estudo", organizado pela Secção Portuguesa da UIA e pelo Sindicato Nacional dos Arquitectos, realizou-se em Junho. O segundo, o Encontro Nacional de Arquitectos, foi dinamizado por um "grupo de arquitectos de Lisboa" com o apoio do SNA e realizou-se em Dezembro.

O ano de 69, para além das eleições à Assembleia Nacional, foi ainda palco de debates críticos sobre o problema da habitação, quer no II Congresso Republicano de Aveiro (Maio de 69), quer no Colóquio sobre Política

\footnotetext{
${ }_{19}$ Nuno Portas; Bartolomeu Costa Cabral; Francisco Silva Dias, Carta ao Director da ESBAL, 6 de Março de 1969, p. 1. Arquivo Francisco Silva Dias.

20 Ibidem: 3.

${ }^{21}$ Nuno Portas, Carta ao Professor Sebastião Formosinho Sanchez, Outubro 1969, p. 5. Arquivo Francisco Silva Dias.
} 
de Habitação (Julho de 69), procurando reenquadrar o exercício da profissão na sociedade em profunda transformação (Bandeirinha, 2007: 70-86).

O encontro de Junho é dinamizado por professores da ESBAP, Fernando Távora e da ESBAL, Bartolomeu Costa Cabral e Nuno Portas, e ainda por membros da SNA, Pires Martins e da UIA, Manuel Tainha e Manuel Moreira. Focado no "futuro da formação do arquitecto", o II Encontro de Estudo debateu o problema do novo edifício da ESBAL, nomeadamente a sua localização e programa, considerando as propostas de Manuel Tainha e Carlos Ramos desenvolvidas no início da década de 60.

A reestruturação do ensino, no contexto da crise com que se deparam as duas escolas, foi também discutida e potenciada pelo orador convidado, o arquitecto italiano da Escola de Milão, Vittorio Gregotti. Na sua intervenção, Gregotti defendeu que "a Universidade do futuro deverá ser crítica e baseada numa grande flexibilidade de programas de ensino, nos quais a participação dos estudantes terá uma importância fundamental", ${ }^{22}$ integrando no seu discurso o debate sobre a autogestão que levou ao encerramento de todas as escolas de arquitectura italianas em 1964. ${ }^{23}$ Seis meses mais tarde, os arquitectos, professores e estudantes voltavam a reunir-se. As piores previsões sobre o "futuro da formação do arquitecto" tinham-se confirmado: no Porto, o curso de arquitectura estava encerrado e em Lisboa, Nuno Portas, assistente responsável por três das cadeiras nucleares do curso tinha acabado de apresentar a sua demissão.

A 6 de Dezembro dirigem-se para a Sociedade Nacional de Belas-Artes 84 estudantes e 45 estagiários das ESBA de Lisboa e do Porto, para participar durante três dias no Encontro Nacional de Arquitectos.

Os estudantes e assalariados unem-se em volta do tema 6, "Arquitectura e Burocracia" que se fundiu com o tema do "Sindicalismo", e apresentam uma moção ao Encontro, entrando em ruptura com o próprio SNA, onde propõem "um movimento já iniciado, dos sectores de assalariados e estudantes, que consideramos a única via de resolução dos problemas concretos da actividade do arquitecto" contra as "actuações oportunistas, mistificadoras e demagógicas". ${ }^{24}$

O debate ficou marcado pela participação excepcional dos mais novos, que alimentou o confronto com os mais velhos, provocando talvez pela primeira vez na história dos encontros de arquitectos, segundo Raul Hestnes

\footnotetext{
22 "A formação do arquitecto ante o mundo em evolução - objecto de debate no II Encontro de Estudo", Primeiro de Janeiro, 22-6-1969. Arquivo Fernando Távora.

${ }^{23}$ Ver o n 287 da revista Casabella, intitulado "Debatitto suole scuole de architetura in Italia".

${ }^{24}$ Comissão Organizadora do Encontro Nacional de Arquitectos (ENA) de 1969, Encontro Nacional de Arquitectos, p. 4. Arquivo Francisco Silva Dias.
} 
Ferreira, um "desencontro de gerações" (apud Duarte, 1969: 202). Este "desencontro" não permitiu gerar consensos, dando início a um processo aberto, alicerçado, segundo Carlos Roxo "no desejo de vencer o medo", onde, como escreve Nuno Teotónio Pereira, "os arquitectos tomaram consciência do seu papel na sociedade", afastando o debate da disciplina e deslocando-o para a política (ibidem: 202-207).25

Da Escola de Lisboa estavam presentes professores e alunos, sendo Francisco Silva Dias um dos principais dinamizadores do encontro. Participaram no entanto poucos arquitectos e professores da Escola do Porto, ao contrário dos estudantes, que, perante a crise na Escola, aderiram em massa ao encontro. Os estudantes do Porto e de Lisboa, movidos pelo combate político dentro da Escola, recusaram os caminhos propostos no debate e centraram na própria Escola a refundação possível, quer pedagógica quer do próprio exercício ou função da profissão (Bandeirinha, 2007: 88-90; Costa, 1982: 81). Consolida-se, assim, a "plataforma giratória entre o atelier e a Escola", como identifica Jorge Figueira, onde "se funda uma prática de resistência cultural e política ao regime” (Figueira, 2002: 57).

As consequências dos acontecimentos ocorridos no ano de 1969 não são lineares, mas segundo Leopoldo C. Almeida (apud Duarte, 1969: 201): "[...] o jogo tal como tem sido jogado até aqui acabou. Há um novo jogo: o da tomada de consciência individual [...]". Também no ensino era necessário jogar um novo jogo. A tentativa de pôr a funcionar um modelo moderno tinha chegado ao fim, deixando em aberto a construção de um novo paradigma que possibilitasse, através da "tomada de consciência individual", a construção de uma "obra colectiva", como também se reclamava no encontro. Estavam assim criadas as condições para uma formação social do arquitecto.

\section{Experiências pedagógicas: 1970}

Em Janeiro de 1970, José Veiga Simão toma posse como Ministro da Educação Nacional, iniciando a preparação do Projecto do Sistema Escolar e das Linhas Gerais da Reforma do Ensino Superior, aprovada em Janeiro de 1971. Relativamente à reforma do ensino artístico, Veiga Simão solicita uma proposta a Frederico George e autoriza o funcionamento de regimes experimentais no Porto e em Lisboa. Com esta medida, o ministro compreende a necessidade de criar condições para uma reformulação dos cursos de arquitectura, que não fosse meramente tecnocrática, potenciando

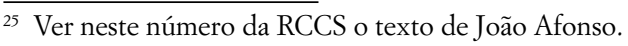


a auto-reflexão no interior dos próprios cursos, e fazendo assim regressar professores e alunos à Escola.

No Porto, a "Experiência" funcionou entre Abril e Julho de 1970 sob a coordenação de uma comissão paritária com três professores (Filgueiras, Távora e Gigante) e três alunos (Ricardo Figueiredo, José Garrett e Rui Louro) sob o tema "Escola de Arquitectura".

Em Lisboa, Frederico George promoveu, entre 1970 e 1971, uma experiência pedagógica através da contratação de novos assistentes, entre os quais Raul Hestnes Ferreira, Francisco Pires Keil do Amaral, Manuel Vicente e Tomás Taveira, onde se desenvolveu a coordenação horizontal entre as disciplinas do mesmo ano.

Estas experiências, de modelos e resultados distintos, ${ }^{26}$ convergiram na recusa da Reforma de 57, no abandono de uma pedagogia reduzida ao virtuosismo do desenho e na aposta na arquitectura, ou na Escola, como campo de experimentação e reflexão para a transformação da sociedade.

Numa palestra sobre os resultados da experiência no Porto, Fernando Távora afirma um novo posicionamento da escola: "Fartos de práticos estamos nós e o que é necessário é gente com sólida formação teórica" ${ }^{27}$ No entanto, no ano seguinte, os estudantes do Porto enterravam a "experiência" e Raul Hestnes demitia-se da ESBAL, ambos considerando haver um retrocesso no processo de experimentação.

Apesar da resistência do governo, estavam lançadas as bases para uma nova orientação da formação do arquitecto. A formação social do arquitecto, onde o "social" poderia também ser substituído por "político", apoiava-se num sistema flexível de articulação entre cadeiras, no trabalho da escola sobre o meio social, e fundamentalmente na participação activa dos estudantes, assistentes e professores nos órgãos de gestão da escola. No entanto, esta formação teria de esperar por Abril de 74 para se consolidar como estrutura legal. Neste sentido, a revolução nas escolas teria de esperar pela revolução na sociedade.

\footnotetext{
${ }^{26}$ No Porto, o regime experimental funcionou de acordo com um despacho do Ministro, autorizando um programa apresentado pela comissão coordenadora, e tinha como objectivo produzir um relatório, que foi entregue, para servir de base a um novo regulamento do curso de arquitectura. Em Lisboa, pelo contrário, Frederico George é convidado a preparar uma nova reforma e simultaneamente põe em prática uma experiência pedagógica que envolvia apenas as cadeiras de Composição de Arquitectura.

${ }_{27}$ "A interessante experiência realizada na Escola de Belas Artes com o curso de Arquitectura - objecto de uma palestra do Arquitecto Fernando Távora”, Jornal de Notícias, 6-I-1971. Arquivo Fernando Távora.
} 


\section{Consequências: a democracia}

A revolução de 1974 intensificou o debate sobre a formação social do arquitecto, levando os professores e alunos do Porto, por um lado, a sair da Escola para participar no programa $\mathrm{SAAL}^{28} \mathrm{e}$, por outro lado, a construir novas bases para o curso de arquitectura.

O programa SAAL constituiu uma espécie de laboratório de experimentação sobre novas metodologias de projecto, consolidando todo o debate promovido ao longo da década anterior. Este método de projecto procurou conhecer para compreender, mas também dialogar para intervir, tentando encontrar outras formas de construir o espaço urbano e o espaço habitacional na democracia (Bandeirinha, 2007). O SAAL foi assim a ponte entre o debate lançado na década de 60 e os diversos debates sobre a função do arquitecto e da arquitectura gerados no final do século com a democracia, com a entrada de Portugal na Comunidade Europeia ou com a nova ordem política mundial.

Também no curso de arquitectura professores e alunos envolveram-se na reorientação do ensino, promovendo anualmente as "Bases Gerais" (Costa, 2007: 220; Figueira, 2002) como alternativa à Reforma de 57, ainda formalmente em vigor. Estas "Bases" deram origem à entrada da arquitectura na universidade (1979) e à criação das faculdades de arquitectura do Porto e de Lisboa. Mas longe de se iniciar um processo pacífico de integração, a universidade veio colocar novos problemas quantitativos e qualitativos à formação do arquitecto. Quantitativos, porque, com a democracia, a proliferação das universidades deu origem à proliferação dos cursos de arquitectura. Qualitativos, porque a universidade exigiu que a arquitectura apostasse na construção de um corpo científico de aplicação prática nem sempre compatível com a sua matriz artística, técnica e social.

A universidade acabou por transferir para os cursos de arquitectura a crise que ela própria vinha atravessando e que Boaventura Sousa Santos caracterizou como uma "crise de hegemonia" (Santos, 1996: 168). É uma crise provocada, de um modo geral, pela massificação do sistema, pondo em causa a vocação elitista, educativa e teórica da universidade clássica e exigindo uma aproximação à "comunidade" e à "produtividade", adequados à universidade moderna (Santos, 1996: 174-182). Neste sentido, assiste-se a uma progressiva homogeneização de todas as áreas do conhecimento pelos critérios das ciências exactas, que o Processo de Bolonha veio recentemente a legitimar.

${ }_{28}$ Serviço de Apoio Ambulatório Local criado em Agosto de 1974 pelo secretário de Estado da Habitação e Urbanismo, sendo Alexandre Alves Costa coordenador do SAAL Norte. 
A criação dos novos cursos na Faculdade de Ciências, como em Coimbra (1988) ou Guimarães (1996), gerou processos de reacção semelhantes aos da década de 60 pela afirmação da autonomia disciplinar da arquitectura quer ao nível pedagógico, onde as disciplinas científicas foram sendo retiradas dos planos de estudo, quer ao nível da investigação, onde os critérios científicos invadem e condicionam o campo da arquitectura.

Perante este difícil equilíbrio entre a arquitectura e a ciência, a formação social do arquitecto poderá continuar a dar resposta a uma formação generalista a partir da centralidade do projecto, tal como tem vindo a ser defendida pela maioria das escolas de arquitectura, integrando, como propõe Alves Costa, "imaginação com racionalidade" (Costa, 2007: 228).

Neste sentido, o objectivo social da formação do arquitecto não recusa o conhecimento científico, mas torna-o operativo para compreender a complexidade do real, fazendo convergir a formação do projectista com a formação do investigador na resolução dos problemas que se colocam à "comunidade".

Assim, os processos de "participação" 29 envolvendo arquitectos e estudantes de arquitectura na construção de projectos públicos, na gestão do território ou nas operações humanitárias reflectem a operatividade do projecto como instrumento de intervenção e investigação e do arquitecto com função social.

\section{Referências bibliográficas}

Amaral, Francisco Keil do (1958), "A reforma do ensino de Belas-Artes", Arquitectura, 63: 43 .

Bandeirinha, José António (2007), O processo SAAL e a arquitectura no 25 de Abril de 1974. Coimbra: Imprensa da Universidade de Coimbra.

Costa, Alexandre Alves (1982), Dissertação Expressamente Elaborada para o Concurso de Habilitação para Obtenção do Título de Professor Agregado e Constituindo Trabalho Original sobre Assunto Respeitante às Cadeiras do $1^{\circ}$. Grupo do Curso de Arquitectura da Escola Superior de Belas Artes do Porto por Alexandre Vieira Pinto Alves Costa em Dezembro de 1979 a que também se poderia chamar Desastres de Sofia ou Memórias de um Burro. Porto: Edições do Curso de Arquitectura da E. S. B. A. P.

Costa, Alexandre Alves (2007), Textos Datados. Coimbra: eldlarq.

Duarte, Carlos S. (1968), "O Concurso e a Escola”, Arquitectura, 105-106: 179, 230.

${ }_{29}$ Ver os estudos de caso apresentados na segunda parte desta revista sob o tema da "Reflexão sobre inovação e criatividade participativa, a partir de algumas experiências internacionais de gestão do território". 
Duarte, Carlos S. (1969), "Encontro Nacional de Arquitectos”, Arquitectura, 110: 200-207.

ESBAL (1957), Livro de Actas do Conselho Escolar da ESBAL. Arquivo Histórico da Faculdade de Belas Artes da Universidade Técnica de Lisboa.

Figueira, Jorge (2002), Escola do Porto: um mapa crítico. Coimbra: eldlarq.

Filgueiras, Octávio Lixa (1985), A função social do arquitecto: para uma teoria da responsabilidade numa época de encruzilhada. Porto: ESBAP. [1ª ed., 1962]

George, Frederico (1964), Considerações sobre o ensino da arquitectura. Lisboa: Minerva.

Gravata, Adérito da Conceição et al. (1961), "Depois da reforma: um depoimento sobre o ensino de Arquitectura na E.S.B.A.L.”, Arquitectura, 72: 37-51.

Gregotti, Vittorio (1964), "Facoltà del Construire”, Casabella, 287: 19-20.

Hultberg, Erik; Seablom, Seith (1968), "Una casa è una casa”, Casabella, 324: 20-45.

Montez, Paulino (1959) "Palavras do Director da Escola, Prof. Arquitecto Paulino Montez proferidas em 20 de Novembro de 1957 quando o corpo docente agradeceu ao governo a reorganização do ensino", Boletim da Escola Superior de Belas Artes de Lisboa, 1, 35-37.

Portas, Nuno (1968), "Ideias para a zona central de Olivais, Lisboa”, Arquitectura, 103: 110-121.

Ramos, Carlos (1957) "Preâmbulo", VI Exposição Magna da Escola Superior de Belas Artes do Porto. Porto: Escola Superior de Belas Artes.

Ramos, Carlos (1958), "Preâmbulo", VII Exposição Magna da Escola Superior de Belas Artes do Porto. Porto: Escola Superior de Belas Artes.

Santos, Boaventura Sousa (1996), Pela Mão de Alice. O social e o político na pós-modernidade. Porto: Edições Afrontamento. 